\title{
Increasing Microstrip Patch Antenna Bandwidth by Inserting Ground Slots
}

\author{
Yahya S. H. Khraisat \\ Department of Electrical and Electronics Engineering, Al-Huson University College, Al-Balqa' Applied University, \\ Al-Huson, Jordan \\ Email: Yahya_khr@bau.edu.jo
}

How to cite this paper: Khraisat, Y.S.H. (2018) Increasing Microstrip Patch Antenna Bandwidth by Inserting Ground Slots. Journal of Electromagnetic Analysis and Applications, 10, 1-11. https://doi.org/10.4236/jemaa.2018.101001

Received: December 7, 2017

Accepted: January 28, 2018

Published: January 31, 2018

Copyright (c) 2018 by author and Scientific Research Publishing Inc. This work is licensed under the Creative Commons Attribution International License (CC BY 4.0).

http://creativecommons.org/licenses/by/4.0/

\begin{abstract}
Microstrip patch antenna (MPA) is widely implemented in different communication systems. One of the main disadvantages of MPA which limits its applications is its narrow bandwidth. In this paper I enhanced the bandwidth of MPA by inserting multiple slots in its ground plane. I used FR-4 substrate to design this antenna. The dimensions of this antenna are $59 \mathrm{~mm}$ and $79 \mathrm{~mm}$. The dielectric constant is 4.4 and the height is $1.6 \mathrm{~mm}$. I inserted up to 15 slots in ground plane with $1 \mathrm{~mm}$ width. The spacing between slots is $3 \mathrm{~mm}$. I investigated two designs. In the first design, slots were arranged in parallel to the feeding line. In the second one, slots were arranged horizontally to the feeding line. The main objective of this paper is to design and simulate MPA suitable for wide number of applications. Antenna bandwidth improvement is $18 \%$. All the simulations were obtained by using HFSS simulator.
\end{abstract}

\section{Keywords}

Microstrip Patch Antenna, Bandwidth, Ground Slots, HFSS Simulator

\section{Introduction}

The main objective of communication systems is to transmit information bearing signals from transmitter to the receiver via communication channel. The antenna is used in both transmitting and receiving parts to convert voltage or current into electromagnetic signals and vice versa. MPA are commonly used in different Communication systems due to their small size, high gain and their omnidirectional radiation pattern. MPA are used in different applications like wireless communication including mobile communication. They are also used in computer links, remote controls, satellite communication and radar systems. One of their disadvantages is narrow bandwidth. MPA usually consists of a ra- 
diating patch which is made of conducting material such as gold or copper. It can take any possible shape such as rectangular, triangular, square, or circle [1]. The radiating patch and the feed lines are usually inserted on the dielectric substrate as shown in Figure 1.

One of the limitations of this type of antennas is the narrow bandwidth. A lot of techniques are used to improve its performance like Shorted Patch [2], Stacked Shorted Patch [3], Slot-Loading Technique [4] and Slotted Ground Plane [5]. More techniques are continuing to appear in order to make the performance of the MPA better and better.

In [6] authors inserted slots into MPA to improve its bandwidth. It demonstrates the design of slotted microstrip antenna on a substrate of thickness 1.588 $\mathrm{mm}$ that gives wideband characteristics. The illustrated patch antenna provides bandwidth enhancement compared to antenna without slots of the same physical dimensions. The simulation carried using IE3D simulator.

In [7] three different geometry shape, the $\mathrm{U}, \mathrm{E}$ and $\mathrm{H}$ were developed from a rectangular patch of width $(W)=32 \mathrm{~mm}$ and length $(L)=24 \mathrm{~mm}$. Bandwidth improvement was $4.81 \%$ for $100 \mathrm{MHZ}, 28.89 \%$ for $610 \mathrm{MHz}, 9.13 \%$ for $630 \mathrm{MHz}$ and $9.13 \%$ for $110 \mathrm{MHz}$.

In [8] authors improved antenna bandwidth by $25 \%$ by inserting slots on ground plane and stacked patch supported by wall. This design doesn't affect the frequency of operation. In [9] Slots of different shapes such as triangular or rectangular were placed on the ground plane under the feed line of the radiator for bandwidth increasing and impedance matching.

\section{Antenna Design Procedure}

We are going to design rectangular microstrip patch antenna with and without slots on FR-4 dielectric substrate. The dielectric constant is 4.4, substrate height is $1.6 \mathrm{~mm}$. The antenna designed on a substrate of dimension $59 \mathrm{~mm} \times 79 \mathrm{~mm}$. Values of different parameters which we used in antenna design are shown below in Table 1.

The shape of rectangular patch antenna is shown below in Figure 2.

Rectangular Microstrip patch has been designed with $\varepsilon_{r}=4.4$ and $h=1.6 \mathrm{~mm}$. We designed the rectangular patch for $2.4 \mathrm{GHz}$, with dielectric substrate of

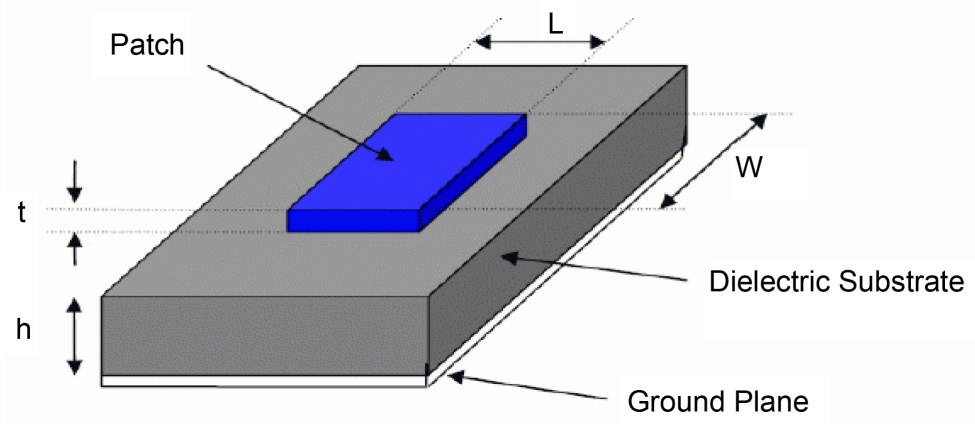

Figure 1. Structure of a microstrip patch antenna. 


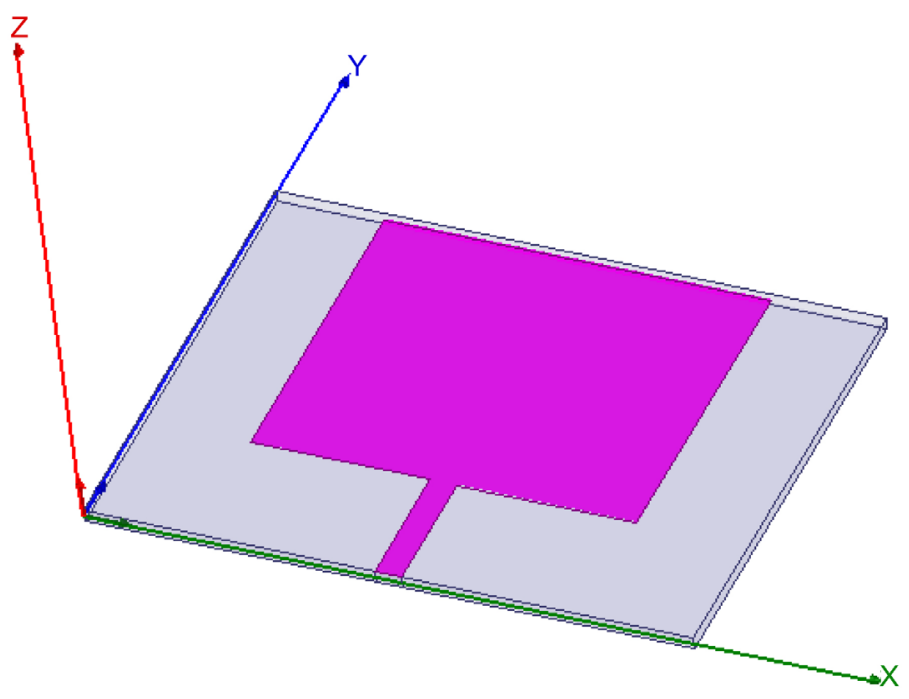

Figure 2. Rectangular microstrip patch antenna.

Table 1. Antenna parameters.

\begin{tabular}{cc}
\hline Parameters & Numerical Values \\
\hline Substrate length & $79 \mathrm{~mm}$ \\
Substrate width & $59 \mathrm{~mm}$ \\
Substrate height & $1.6 \mathrm{~mm}$ \\
Patch length & $50 \mathrm{~mm}$ \\
Patch width & $41 \mathrm{~mm}$ \\
Feeding length & $17 \mathrm{~mm}$ \\
Feeding width & $3.5 \mathrm{~mm}$ \\
Slot width & $1 \mathrm{~mm}$ \\
\hline
\end{tabular}

thickness " $h$ " and relative dielectric constant $\varepsilon_{r}$. The width and length of the patch can be calculated by

$$
W=\frac{c}{2 f\left[\left(\varepsilon_{r}+1\right) / 2\right]^{-1 / 2}}
$$

and

$$
L=\frac{c}{2 f \sqrt{\varepsilon_{e}}}-2 \Delta I
$$

The antenna was designed using HFSS.

\section{Slots in the Ground Plane of Rectangular Patch}

We designed microstrip patch antenna with multiple number of slots. We added up to 15 slots in the ground plane with $3 \mathrm{~mm}$ spacing. The width of each slot is $1 \mathrm{~mm}$. We inserted slots in parallel and horizontally to the feeding line. Each slot line is $2 \mathrm{~mm}$ shorter than the previous one. The design for the parallel slots is shown below in Figure 3. 


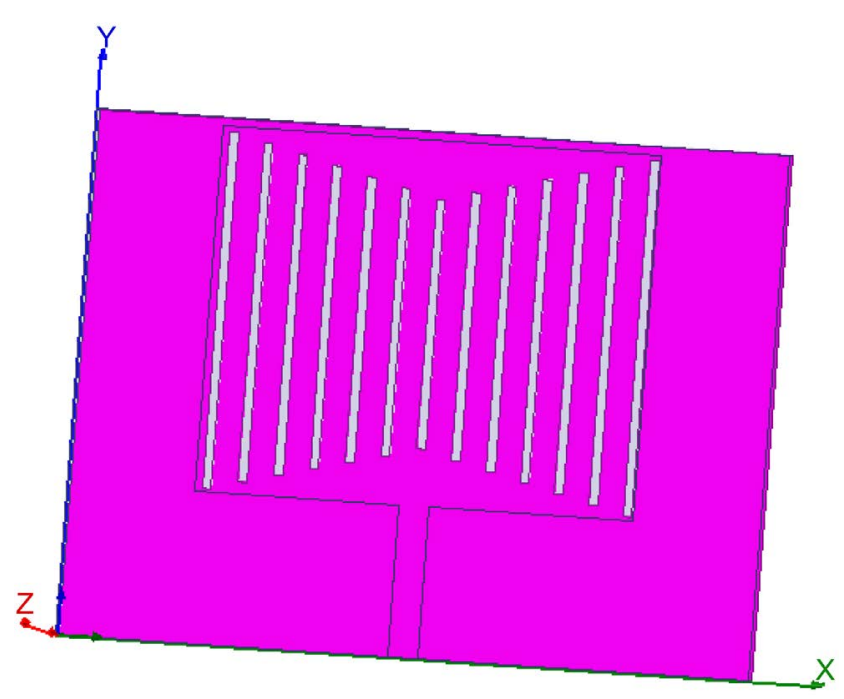

Figure 3. Microstrip patch antenna with slots in ground plane.

The formulas we used to calculate the length and width of patch are shown below.

$$
\begin{gathered}
\varepsilon_{\text {reff }}=\frac{\epsilon_{r}+1}{2}+\frac{\epsilon_{r}-1}{2} \sqrt{1+12(h / w)} \\
\Delta L=0.412 h \frac{\left(\varepsilon_{\text {reff }}+0.33\right)\left(\frac{w}{h}+0.264\right)}{\left(\varepsilon_{\text {reff }}-0.258\right)\left(\frac{w}{h}+0.8\right)}
\end{gathered}
$$

\section{Simulation and Results}

The proposed antenna was simulated by using HFSS (High Frequency Structure Simulator) as shown in Figure 4.

The simulated reflection coefficient of this antenna is shown below in Figure 5.

The resonance frequency is $2.80 \mathrm{GHz}$.

The gain of this antenna is shown below in Figure 6.

The antenna gain is $1.0917 \mathrm{~dB}$.

Radiation Pattern of this antenna is shown below in Figure 7. It is an omnidirectional one.

But we still have small region of no coverage in the direction of 0 and -180 degrees.

In this simulation I used: slot width $1 \mathrm{~mm}$, spacing between slots $3 \mathrm{~mm}, 4 \mathrm{~mm}$ distance between the first slot and the edge of the patch and $4 \mathrm{~mm}$ distance between the last slot and the other edge of the patch.

Vetically inserted slots are shown below in Figure 8. We inserted 13 slots.

The simulated reflection coefficient for this design is shown below in Figure 9.

We have three resonance frequencies $1.5 \mathrm{GHz}, 2.84 \mathrm{GHz}$ and $3.43 \mathrm{GHz}$ which 


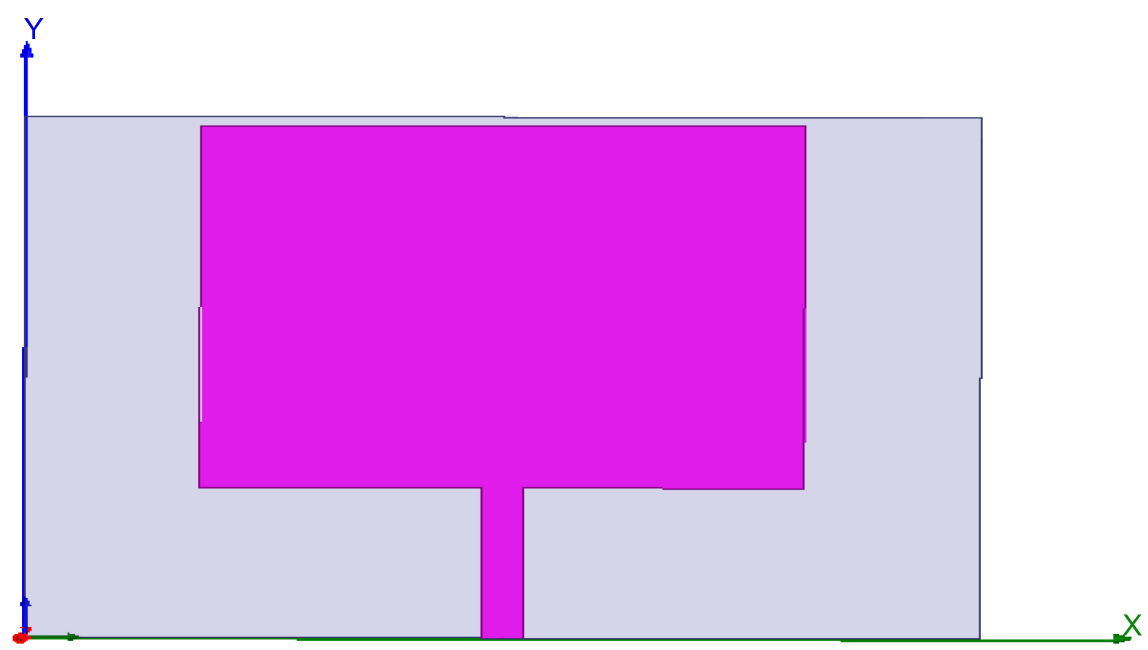

Figure 4. Microstrip patch antenna design.

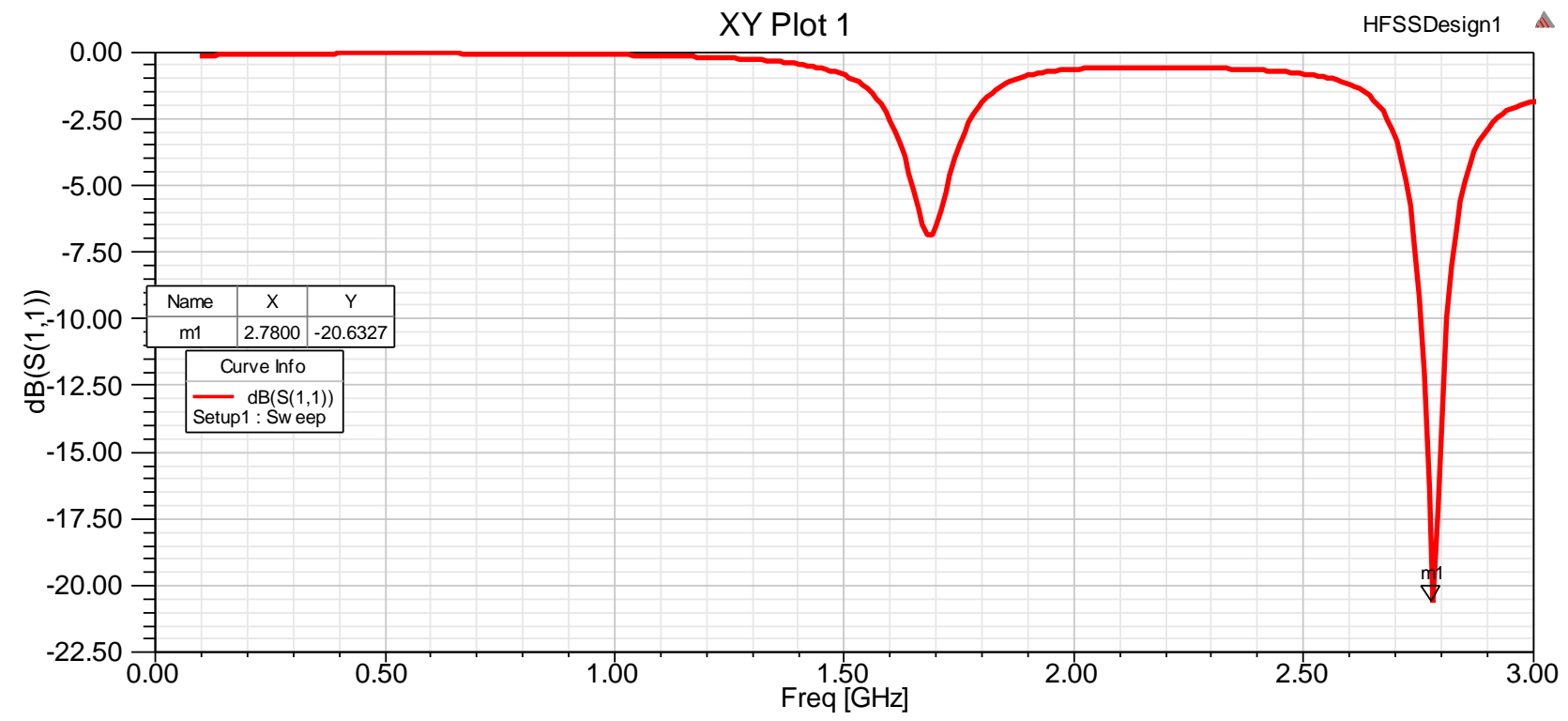

Figure 5. Simulated reflection coefficient of the MPA.

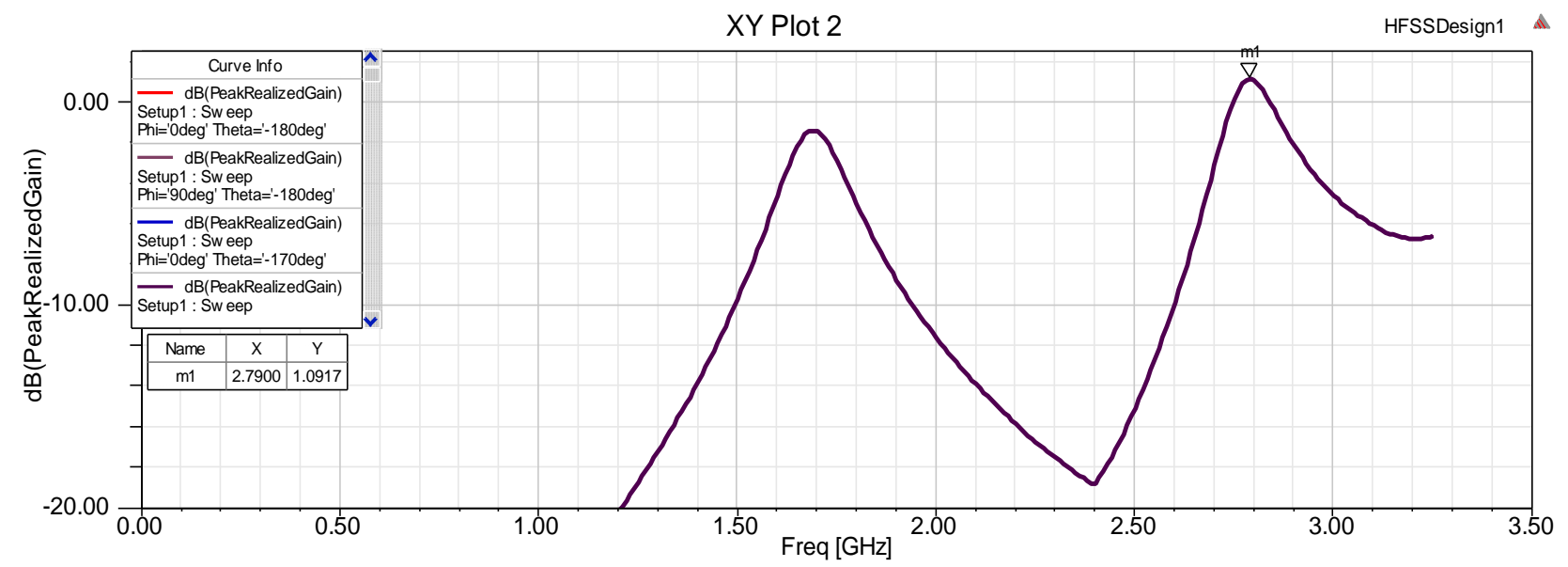

Figure 6. The gain of rectangular MPA. 


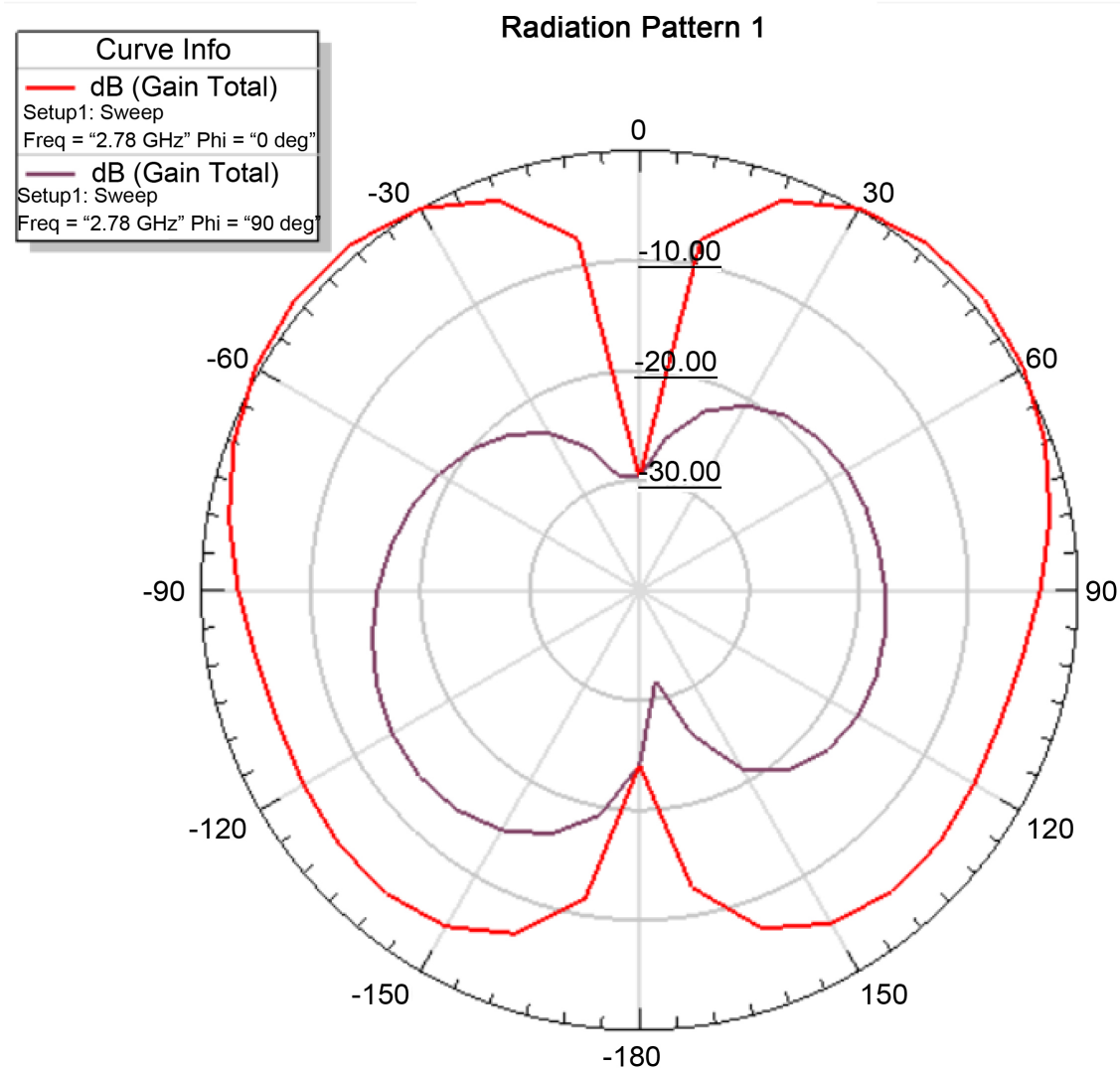

Figure 7. Radiation pattern of rectangular MPA.

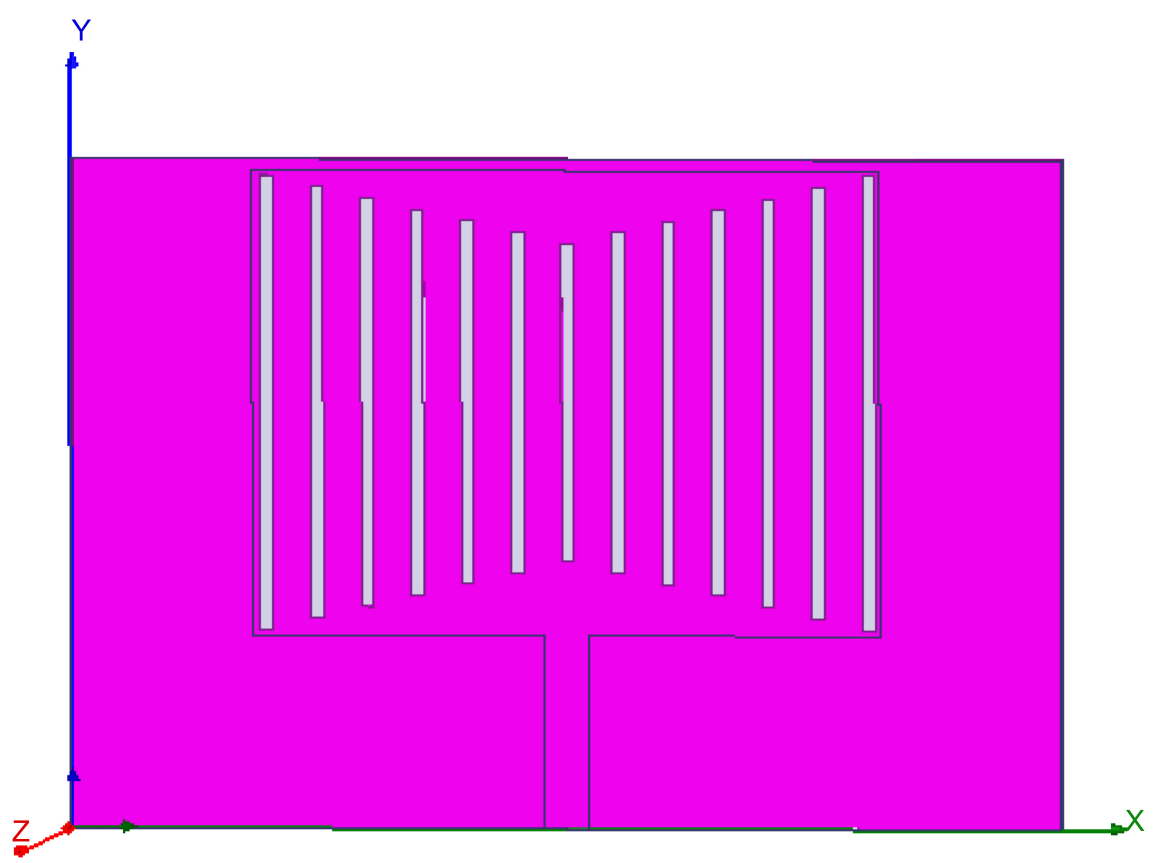

Figure 8. Vertically inserted slots in the ground plane.

makes this design suitable for cognitive radio applications.

The gain of this antenna is shown below in Figure 10. 


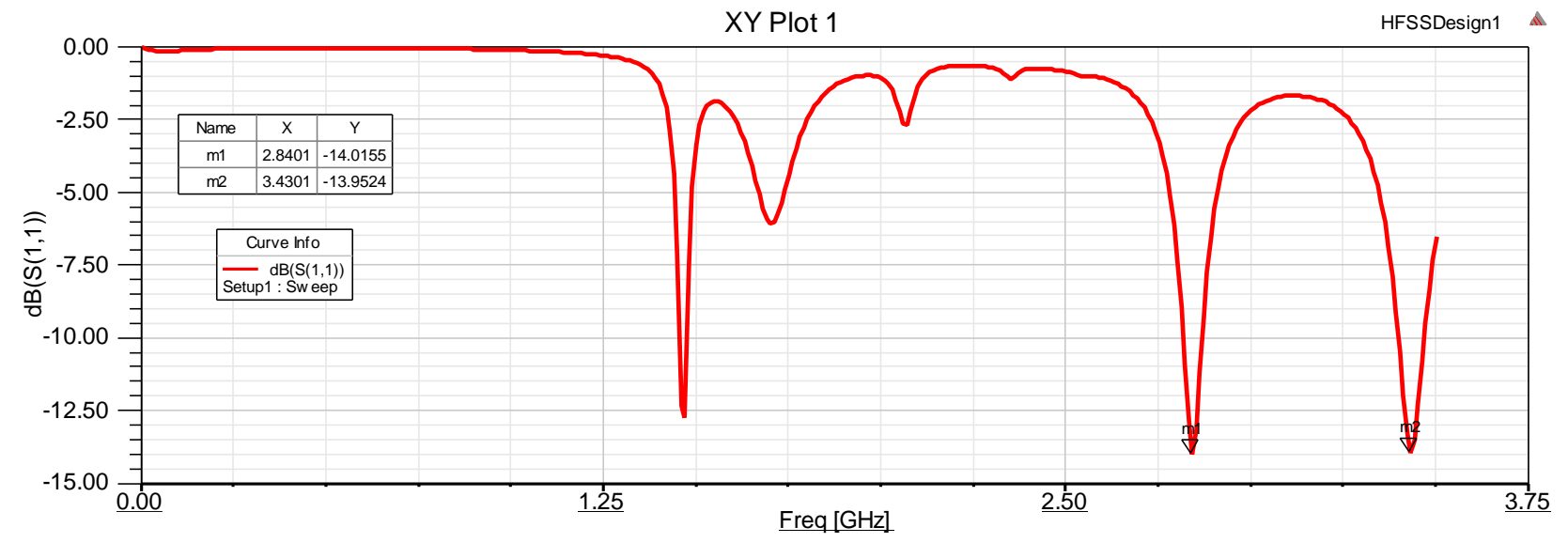

Figure 9. Simulated reflection coefficient for the vertically inserted slots.

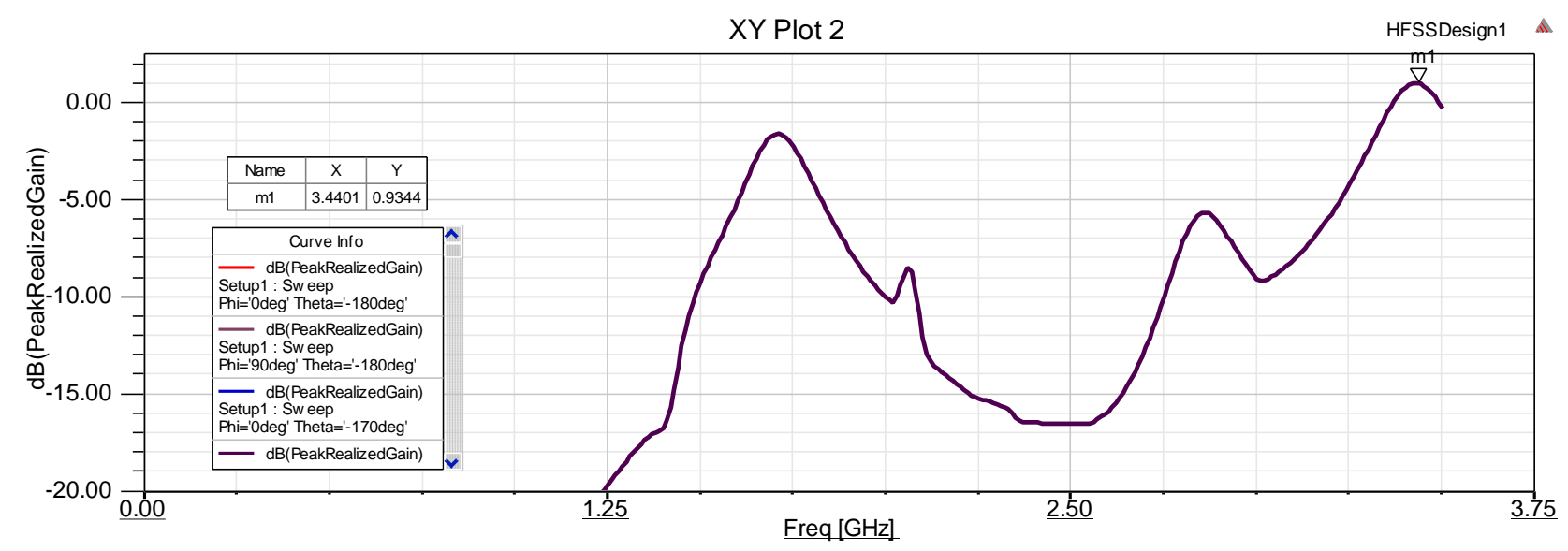

Figure 10. Antenna gain of the vertically inserted slots.

The gain of this antenna is $0.9344 \mathrm{~dB}$.

Radiation pattern of this antenna is shown below in Figure 11.

We observed omnidirectional antenna with better coverage comparing with traditional one.

The horizontally inserted slots are shown below in Figure 12. We inserted 9 slots.

The simulated reflection coefficient for this design is shown below in Figure 13.

In this case we have single resonance frequency at $2.80 \mathrm{GHz}$.

The gain of this designed antenna is shown below in Figure 14.

The gain of this antenna is $1.1889 \mathrm{~dB}$.

The radiation pattern of this design is shown below in Figure 15.

The results of simulation for horizontally inserted slots are the same as that for microstrip patch antenna without slots.

Results of simulation for Return loss characteristics of the designed MPA is shown below in Figure 16.

We compared the results of simulation for the antenna with vertically inserted slots to the results of simulation for the case without slots. 


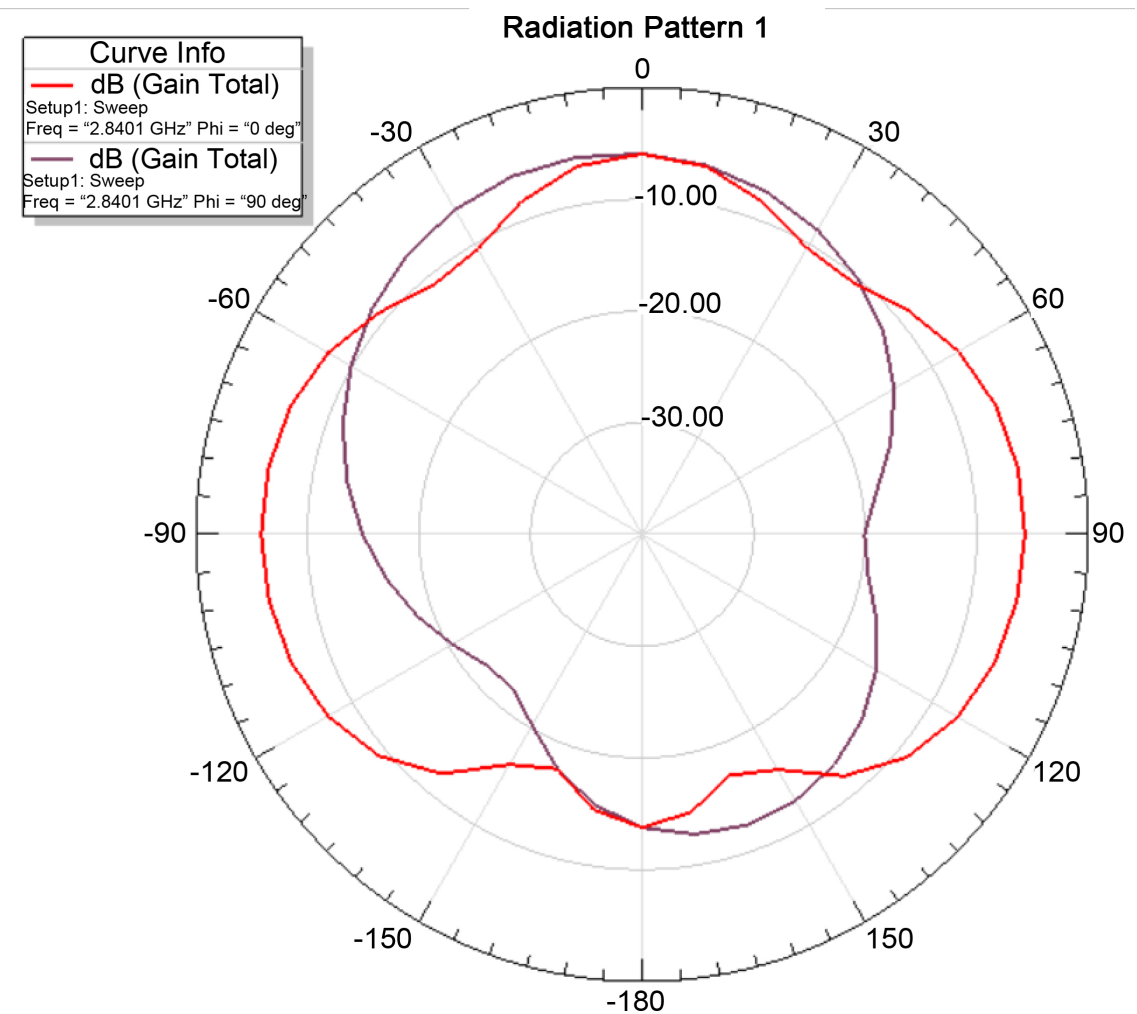

Figure 11. Radiation pattern of this antenna.

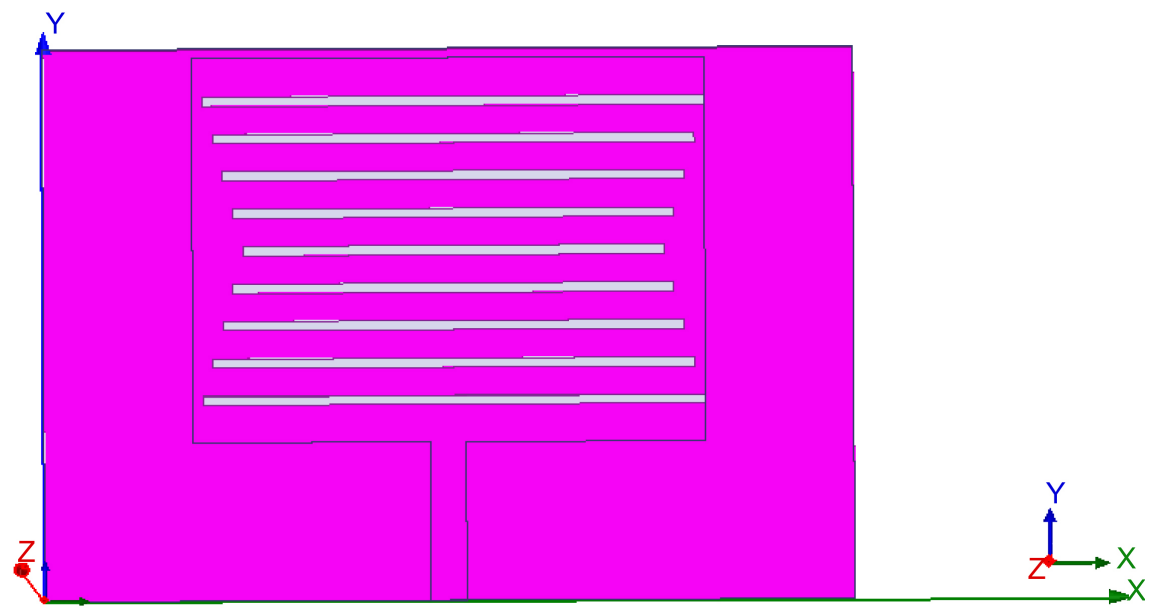

Figure 12. Horizontally inserted slots.

We can see that the conventional patch antenna without slots exhibit only one resonant frequency at $2.8 \mathrm{GHz}$, whereas with vertically inserted slots in the ground plane the patch antenna exhibits multiple number of resonant frequency with one wide band frequency response, at $1.4 \mathrm{GHz}$ and $1.80 \mathrm{GHz}$. Wide band response is observed from $2.43 \mathrm{GHz}$ to $2.97 \mathrm{GHz}$ approximately. It can also be shown from the above figure that the $-10 \mathrm{~dB}$ bandwidth is also increased with slots. The bandwidth of patch antenna without slot is $47 \mathrm{MHz}$, whereas the bandwidth of patch antenna with slots is approximately $540 \mathrm{MHz}$. This shows 


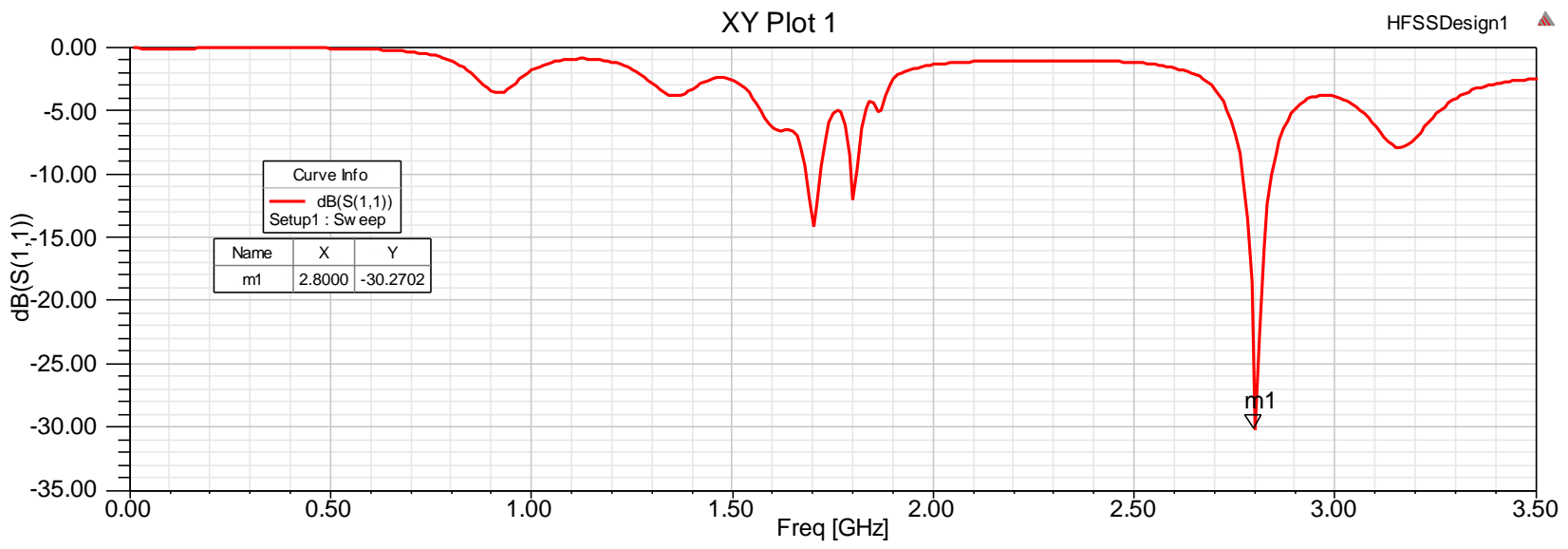

Figure 13. Simulated reflection coefficient for the horizontally inserted slots.

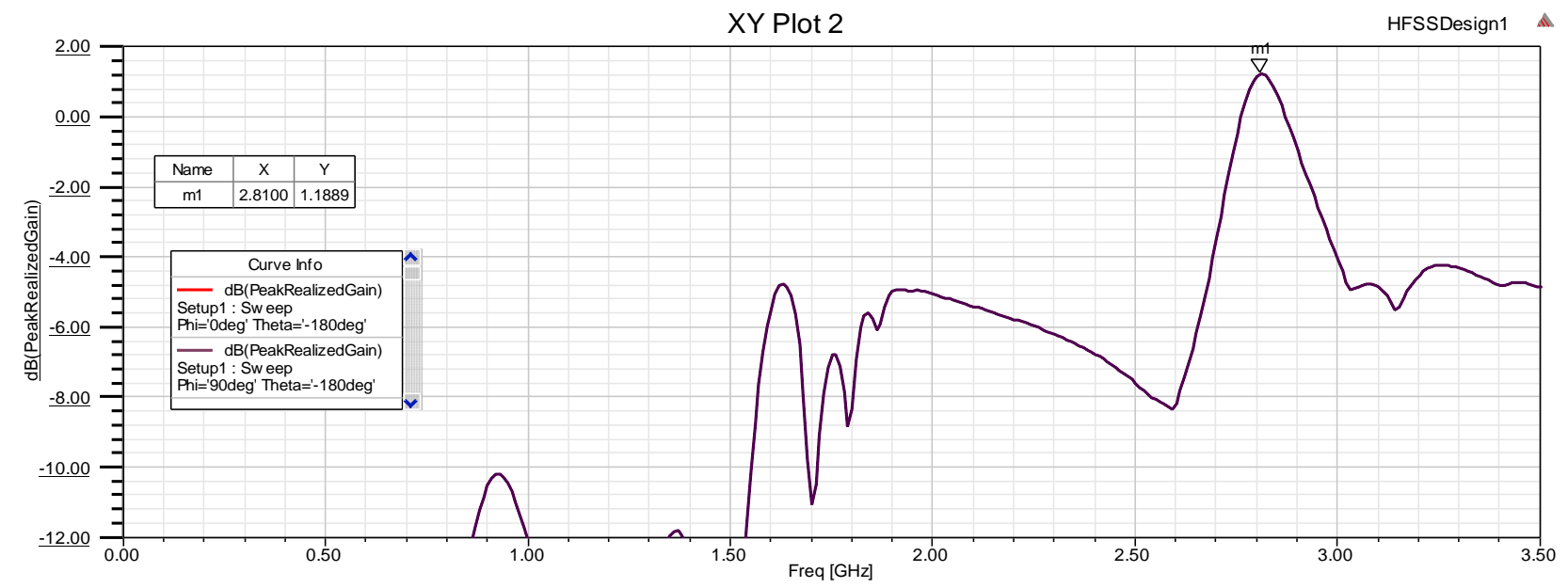

Figure 14. The gain the horizontally insrted slot.

that the bandwidth of patch antenna with slots is enhanced approximately 493 $\mathrm{MHz}$ with respect to conventional antenna. From the above figures it can be shown that the gain of patch and directivity with slots is approximately the same as conventional patch antenna. The gain of patch antenna with and without slots is $1.899 \mathrm{~dB}$ and $2.185 \mathrm{~dB}$ respectively. The directivity of the patch antenna with and without slots is $5.353 \mathrm{dBi}$ and $6.159 \mathrm{dBi}$ respectively.

\section{Conclusion}

In this work, the bandwidth of the microstrip patch antenna has been enhanced using multiple numbers of slots in the ground plane. The multiple bands and a wide band response are achieved by using this technique. From Figure 16, we can see that the simulated results showed very much improvement in the antenna bandwidth while keeping antenna gain and directivity without considerable changing. The antenna shows bandwidth up to $540 \mathrm{MHz}$ compared to the conventional one which was only $47 \mathrm{MHz}$. We obtained 18\% bandwidth improvement. Also inserting vertical slots in ground plane provided omnidirectional antenna pattern with better coverage. This antenna can be used in cognitive radio 


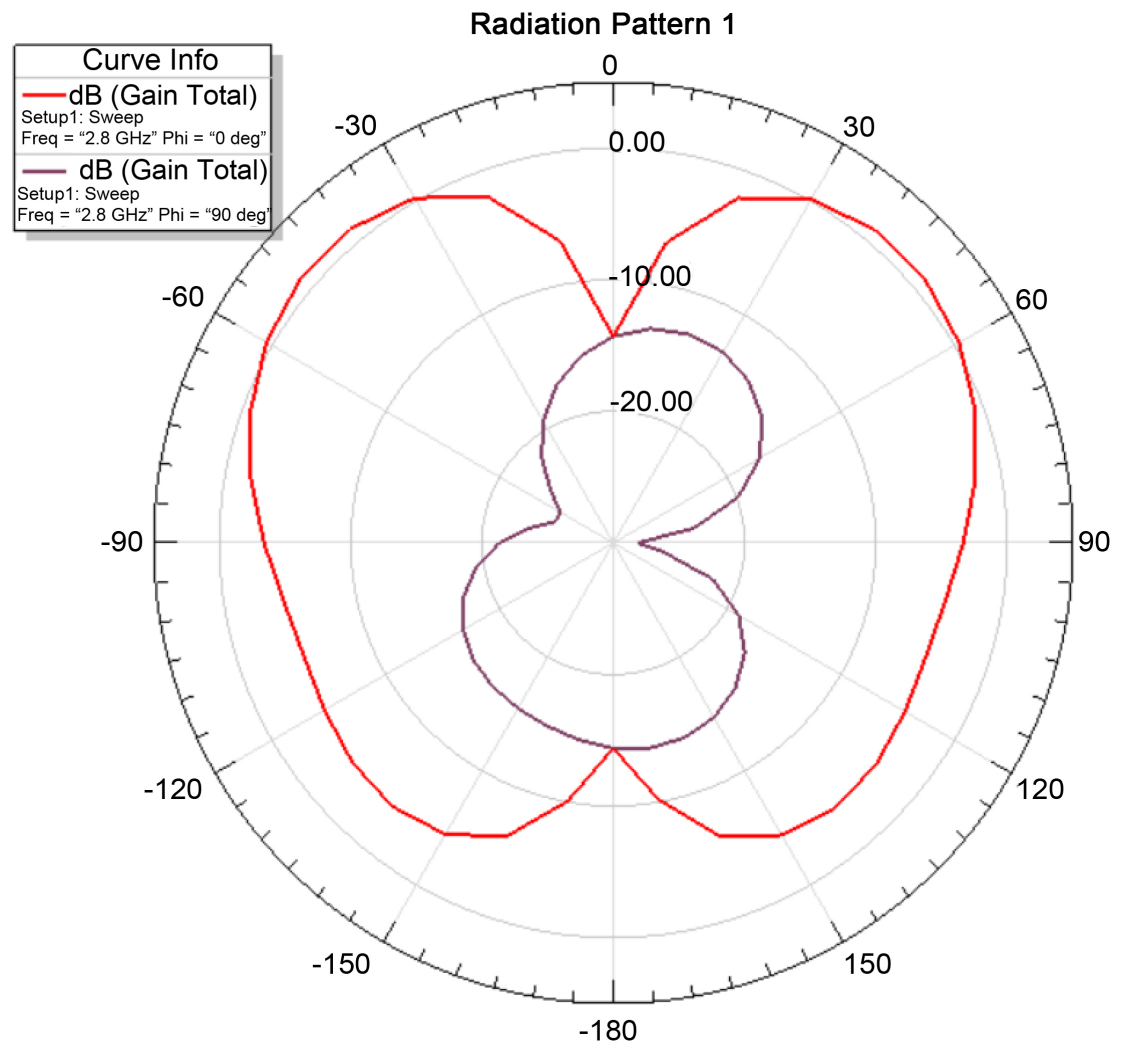

Figure 15. Antenna radiation pattern of the horizontally inserted slots.

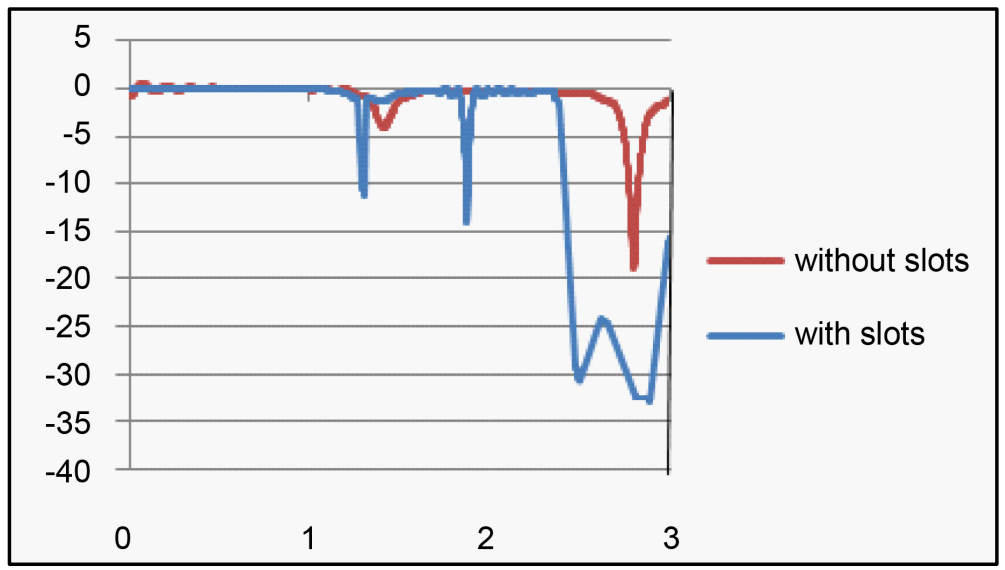

Figure 16. Comparison of simulated return loss characteristics of patch antenna with and without slots.

applications. It can be concluded that the proposed design has been successfully implemented for rectangular patch antenna and also can be used for other types of patch antennas as well.

\section{Acknowledgements}

I am very grateful and thankful to my University "Al-Balqa Applied University" for supporting me in carrying out this research through my sabbatical leave in 
the academic year 2017/2018. My sabbatical leave was at Jordan University of Science and Technology/College of Engineering/Electrical Engineering Department.

\section{Claim}

This work has been carried out during sabbatical leave granted to Prof. Yahya Salameh Khraisat from Al-Balqa' Applied University (BAU) during the academic year 2017/2018.

\section{References}

[1] Khraisat, Y.S.H., Olaimat, M.M. and Abdel-Razeq, S.N. (2012) Comparison between Rectangular and Triangular Patch Antennas Arrays. Applied Physics Research, Canadian Centre of Science and Education, 4, 75-81.

[2] Peixeiro, C. (2011) Microstrip Patch Antenna: An Historical Perspective of the Development. 2011 SBMO/IEEE MTT-S International Microwave and Optoelectronics Conference (IMOC 2011), 684-688. https://doi.org/10.1109/IMOC.2011.6169224

[3] Kumar, P. and Singh, G. (2009) Microstrip Antennas Loaded with Shorting Post. SciRes, 1, 41-45.

[4] Wong, K.L. and Chen, W.S. (1997) Compact Microstrip Antenna with Dual Frequency Operation. Electronics Letters, 33, 54. https://doi.org/10.1049/el:19970433

[5] Usha Kiran, K., Yadahalli, R.M., Vani, R.M. and Hunagund, P.V. (2008) Compact Broadband Stacked Dual Wide Slit Loaded Rectangular Microstrip Antenna. Radio and Space Physics, 37, 366-369.

[6] Thakare, V.V. and Singhal, P.K. (2009) Bandwidth Analysis by Introducing Slots Microstrip Antenna Design Using Ann. Progress in Electromagnetics Research M.

[7] Roy, A.A., Môm, J.M. and Igwue, G.A. (2013) Enhancing the Bandwidth of a Microstrip Patch Antenna Using Slots Shaped Patch. American Journal of Engineering Research (AJER), 2, 23-30.

[8] Abu Tarboush, H.F., Al-Raweshidy, H.S. and Nilavalon, R. (2009) Bandwidth Enhancement for Microstrip Patch Antenna Using Stacked Patch and Slot. IEEE International Workshop of Antenna Technology.

[9] Liu, L., Cheung, S.W. and Yuk, T.I. (2011) Bandwidth Improvements Using Ground Slots for Compact UWB Microstrip-Fed Antennas. PIERS Proceedings, Suzhou. 